UDC: 811.111'255:159.953.5 https://doi.org/10.22190/JTESAP2103321K

Review research paper

\title{
REFLECTIVE PRACTICE AND PREZI - TOOLS FOR IMPROVING ACADEMIC SPEAKING SKILLS
}

\author{
Olivera Korpaš \\ University of Szeged, Hungary
}

\begin{abstract}
This paper aims at investigating the usefulness of the reflective practice supported by technology as a tool for improving academic speaking skills. The study employs two groups of undergraduate students in the Integrated Skills course for Academic Purpose, at the University of Szeged, that undergo the same instruction. The nonexperimental group does not use technology to support their speaking practice, while the experimental group uses Prezi. The instruments used in the research are surveys and the instructor's journal. The results reveal that students perceive reflective practice as a useful tool that helps them think critically about their performance. What is more, the study shows that reflective activities, when combined with online resources boost motivation for speaking and better presentation performance.
\end{abstract}

Key words: self-assessment, reflective practice, English for Academic Purpose, technology, academic speaking skills, Prezi

\section{INTRODUCTION}

Undergraduate students wishing to enroll in graduate and post-graduate programs need to master English for Academic Purpose (EAP) to be able to actively participate in Academia. All four language skills are equally important and should be devoted considerable time for practice. Nonetheless, delivering a presentation in front of experts is an important component of any graduate program. This also includes skills of discussing, forming clear, concise, convincing arguments, and delivering an effective presentation. How can this be mastered? Sadly, there is no one-size-fits-all model and instructors usually develop their own approach.

The author of this article creates and conducts a pilot study during her teaching practice in 2017 which served as a benchmark for a subsequent experimental study in 2018 as a part of her professional development as an EAP practitioner and a researcher. The experimental study was the instructor's PhD project and due to its complexity, it extends into several phases. This paper aims to present the research results from a particular segment of the $\mathrm{PhD}$ project, focusing only on the efficiency of the technology for practicing Academic Speaking.

Submitted December $12^{\text {th }}, 2020$, accepted for publication February $23^{\text {rd }}, 2021$

Corresponding author: Olivera Korpaš. University of Szeged, H-6720 Szeged, Dugonics square 13, Hungary

E-mail: oliverakorpas@gmail.com 


\section{THEORETICAL BACKGROUND}

\subsection{Reflective practice}

Self-reflection and meta-cognitive thinking are well-researched areas in applied linguistics (Desautel 2009, Haukås, Bjørke, and Dypedahl, 2018). Several studies reported on the benefits of self-reflecting for the improvement of language learning skills (Porto 2007, Mynard 2008, Osborn 2005). The most frequent way of reflecting is by using selfassessment practices (Rodriguez Ochoa 2017, Birjandi and Nasrin 2010), a learner's journal (Tuan 2010, Rokni and Asieh 2014), or a learner's portfolio (Lo 2010, Yang 2003, Young and Crow 1992, Gottlieb 1995, Paulson, Paulson and Meyer 1991, Nunes 2004). However, it is not only students who reflect on their performance, but also teachers (Hollingsworth and Clarke 2017, Conway 2001, Zeichner and Liu 2010, LaBoskey 1994, Orlova 2009, Akbari, Behzadpoor, Dadvand 2010). In recent years, language teachers tend to adopt action research to find out how to improve their instruction and provide learners with a better learning experience (Pardede 2019:138-140). In this way, a teacher is a researcher of one's own classroom practice and works on identifying a problem, designing a solution, acting upon the problem, and reflecting on the outcome (Burns 2009: 2). A common tool for investigating one's own teaching is keeping a teacher's diary/journal (Cohen-Sayag and Fischl 2012, Triff and Popescu, 2013).

\subsection{Academic speaking skills and technology}

Students list the fear of producing mistakes in front of their peers and audience, lack of confidence, lack of ideas, and difficult topics as some of the reasons behind their failure to improve their oral communication (Darginavičienè and Šliogerienè, 2020).

Nonetheless, the literature provides many examples of how to improve one's fluency and accuracy (Albino 2017, Derakhshan, Khalili and Beheshti 2016, Zou et al. 2020). The study by Hamad, Metwally, and Alfaruque (2019) shed some light on using YouTube and Audio Tracks Imitation (YATI) to improve EFL speaking skills. The students in the study reported that YATI has a positive impact on their engagement and speaking performance in class. According to Abdulrahman (2018), TED talks is not only used as valuable listening practice, but it can also improve student's communication. It helps not only with pronunciation but also stress and intonation of the words and phrases for academic purpose. In addition, Lancini (2019) reports on the use of Android and iOS voice tools for improving fluency and oral skills. The study shows that video recordings are a motivating tool to reflect on ones' work and instigate encouragement, responsibility, and independence.

However, not many studies combined technology with reflective practice. Kizilcik and Daloglu (2018) devised an interactive reflection model, which involves the teacher as a researcher and students to involve in the reflection to improve their performance. It is a continual cycle of reflecting with students on their reflections using rubrics for selfassessment. These rubrics targeted reflecting upon mini presentations in terms of content, organization, delivery, visual use, and language. Both students and the instructor had undergone continuous self-assessment and it is highly beneficial for both sides.

Since this was the only study of this kind that I could found, it inspired me to think of my own classroom practice and devise a similar practice to contribute to the field. 


\subsection{Prezi}

Prezi is presentation software that gained momentum in recent years. Nonetheless, the company was founded over a decade ago. The difference between PowerPoint and Prezi lies in the layout and features. According to the official Prezi website, the company states that the presentations created in Prezi are more engaging, memorable, and persuasive (PREZI). The features and layout provide for the user's creativity to come to light while presenting in a storytelling way (The SCIENCE OF EFFECTIVE PRESENTATION). As a graduate student myself, I had encountered some colleagues using Prezi during conferences abroad. However, I did not notice that Prezi was being used in our department. I also could not find any studies that used Prezi to improve students speaking skills in the EAP context. Thus, it provided a perfect opportunity to use it in my classes, teach students to present according to the latest trend, and conduct a small experiment.

\section{THE RESEARCH METHODOLOGY}

\subsubsection{The purpose of this study}

This study has two aims. Firstly, to test the usefulness of using reflective practice as a tool in improving student's Academic speaking skills. Secondly, to examine the efficiency of this practice when combined with technology. There is a non-experimental and an experimental group. With the help of the non-experimental group, the first research question is answered, while with the help of the experimental group, both the first and second research questions are addressed:

- Is the self-reflective survey a helpful tool in thinking critically of one's own performance?

- How does technology affect the self-reflective practice in class?

This paper aims to present a segment of the research project that the author carried out towards completing $\mathrm{PhD}$ thesis.

\subsubsection{The settings and participants}

The study was conducted at the Faculty of Humanities and Social Sciences, in Szeged, Hungary. The participants of this study were second and third-year BA students studying at the Institute of English and American studies. The study consisted of two phases. The first phase was in the autumn of 2017 and the second phase was exactly one year later. In both phases, the same instruments were employed. However, participants are different. In both phases, participants of the study were attending the course called Integrated English Language Skills based on the textbook that aimed at improving their English Academic Skills. Nonetheless, this study focuses on looking at a particular aspect of EAP — speaking skills.

\subsection{The study design}

\subsubsection{The Instructor' role and approach}

The instructor in her 2nd and 3rd year of PhD studies opted for the course Teaching Practice for two semesters to fulfill her obligatory requirements towards the completion of her PhD study program. The instructor was teaching English for specific purpose 
before her studies both offline and online, but never at the university level and never an Integrated Language Skills course for EAP. This served as a great opportunity for the instructor to improve her teaching skills for her future teaching of EAP and conduct research. Thus, the role of the instructor is twofold - the instructor and the researcher.

\subsubsection{Speaking activities and their goals}

At the beginning of the course in 2017, students were asked to share their opinion in class on how good their speaking skills in the academic context are. All students agreed that practicing presenting, and presentation skills would be something they could highly benefit from and be able to apply in their near future. Based on this answer, the instructor came up with a plan and speaking activities that could help students become more confident and better prepared for delivering a speech or presentation in front of a large academic audience. The speaking activity was not graded, and it did not influence the final course grade. In this way, the instructor reduced the fear of failure and provided a stress-free learning atmosphere.

To practice speaking, students needed to deliver 15-minute group presentations followed by a 10-minute QA by the audience and short feedback from the instructor. There were 14 working weeks and each week there would be one pair presenting a certain grammar topic/rule relating to speaking for academic purpose. In this way, the instructor wanted to simulate the conference presentation atmosphere and prepare the students for their future presentations at conferences.

However, the instructor wanted students to receive enough chance for practice and think critically of their own performance. To achieve this, the instructor devised a tool that would provide guidelines for students to reflect on and assess their peers' presentations weekly until the time comes to perform a self-assessment. This tool is in the form of a small grid table with specific subcategories students should tick. It was created with 2 purposes for two different activities.

Activity 1 aimed at installing the habit of reflecting upon peer's presentation skills and performance weekly. The expectation is that it would raise students' awareness of what is required for an effective presentation performance. It would also help them think critically of others' performance and prepare mentally for their own performance. It would provide clear guidelines to follow and build self-confidence in the future. The evaluation grid is filled-in in class and passed on to the presenters to reflect on. The tool used is named reflective survey.

Activity 2 is a self-assessment of the given presentation in class. It is a self-reflective report on ones' performance that is filled-in online in CooSpace, soon after the lesson for homework. The report contained the same grid as in activity 1 plus questions 6 and 7 that elicit more information about the usefulness of the practice itself. The students were informed that the answers they enclose could be used for research purposes and that their stated opinion has no influence over their final mark in the course. It is voluntary and the students are the ones who benefit the most from it. The tool used is named the self-assessment survey.

\subsection{The Instrument}

The research questions are answered with the help of a self-assessment survey and the teacher's journal. The reflective Survey was a supporting tool that had another purpose. 


\subsubsection{The Reflective Survey}

The reflective survey was a letter-sized survey grid with the title 'Delivering an effective presentation'. There are four main categories in the grid, each with up to 3 subcategories. The students need to rate their peers' performance on a 5-point Likert scale from 'Very Poor' to 'Excellent'. The four categories are Content/Material, Presentation Skill, Voice Quality, Discussion skills. The same grid was used in the Self-Assessment Survey for questions 2 to 5 .

\subsubsection{The Self-Assessment Survey}

The self-assessment survey aims at self-evaluating one's presenting in class. At the very top of the survey, the purpose is explained. It informs students that the answers they provide could be used for research purpose. The survey was short and contained seven questions. Question 1 simply asked for the student's name or a pseudonym. Questions 2 to 5 are in the form of 4 categories with a couple of subcategories to which a rating scale is attached. Question 6 asked for the level of agreement with the statement about the helpfulness of self-reflecting from 'Strongly Disagree' to 'Strongly Agree'. The last question asked for student's opinions or remarks regarding the activity itself. The same reflective survey was used in the course in 2017 and the one in 2018.

\subsubsection{Instructor's Journal}

Since the surveys cannot capture the whole classroom atmosphere it was necessary to keep a journal that can help the instructor carefully observe and note down the learning process in an objective way. The instructor would note down her observations after each class and when the course ended reflect holistically. Concerning the speaking practice, the instructor devised themes and questions to guide her in forming an objective opinion.

In the non-experimental group, the instructor created themes - students' confidence when presenting without technology, student's overall performance according to the grid from the reflective-practice, classroom, and learning atmosphere during the presentations.

In the experimental group, the instructor created themes - students' confidence when presenting with Prezi, student's overall performance according to the grid from the reflective-practice, classroom, and learning atmosphere during the presentations.

\subsection{The non-experimental and the experimental group}

The same instruments, the same presentation topics, sources, and the same reflective practice were used in both groups. The groups had different participants and the way of delivering a mini presentation was different. In the course of 2017, the students were instructed to deliver the presentation orally with a one-page paper with notes and exercises for the audience. In the course of 2018, the students were instructed to deliver their presentation with Prezi and have a one-page paper with notes and exercises for the audience too. In 2017, students had to rely on themselves when it comes to creativity and grabbing the audience's attention, while in 2018 the students would use Prezi and project their presentation on the wall. None of the students were acquainted with the notion of Prezi for making presentations or knowing how to use it. By changing the mode of delivery of presentations and using a completely unknown online resource to the students, we wanted to see whether the designed self-reflective activities for improving speaking skills would be at stake. 


\section{DATA ANALYSIS}

A descriptive analysis of 'Self-assessment surveys' of 2017 and 2018 is presented in the following subsections.

\subsection{Self-Assessment Survey in 2017}

Question 1 elicited that fifteen out of twenty students had reflected upon their classroom mini-presentation performance. Question 2 was related to the content/material of students' presentations. Most students have evaluated the structure of their presentation and the amount of material as something that they have done well. However, more than half acknowledged a lack of visual aids. Question 3 was referring to the student's presentation skills. The question contained 3 subcategories. In terms of eye contact, almost half acknowledged not establishing good eye contact with the audience. The style of presentation was quite good by most students, and timekeeping was only in two cases described as poor. Question 4 had to do with voice quality. An insignificantly small number of students stated that their voice clarity, tone, and speed of speech were poor. Question 5 was relating to discussion skills. Just three students recognized their handling of the questions and responding appropriately as a problem. The majority answered positively.

Question 6 was about acknowledging the usefulness of 'Self-reflecting'. Ten students answered positively and acknowledged that the self-reflection report made them think critically and pointed out their weaknesses that need improvement. Four students were neutral and only one student disagrees. Question 7 asked for personal opinion/remark of the activity itself. There were only four comments/remarks which could be categorized in the following way:

- Thinking critically about your performance:

"I think I need to improve to some extent in every possible way. This report helped me to think about our performance with Dávid critically. Personally, next time I should concentrate more on eye contact (which if I remember well I totally missed) and on the presentation skill itself."

- Not seeing the point: I personally believe that most of us didn't take this presentation too seriously, cause it had no real stake.

- The noticed drawback of the self-reflection report:

"At the discussion part, I ticked "good" because I asked if anyone had questions and at the "responding appropriately" part I put "poor" only because there was no question to respond to."

- Dislike of the activity:

"I hate group presentations."

\subsection{Self-Assessment Survey in 2018}

Question 1 elicited that all students $(25 / 25)$ had reflected upon their classroom minipresentation performance. Question 2 shows us that only 1 student rated his amount of the presentation material as poor. Only four out of 25 rated their poor use of visuals. Question 3 indicated that there is a small number of students that struggle with maintaining eye contact with the audience, and their presentation style. Only one student had poor timekeeping. Question 4 shows that voice clarity, tone/volume, and speed of 
talking was not a significant problem for the group. Question 5 demonstrated very good discussion skills and an insignificant number of students have mentioned this as an obstacle. Question 6 shows that only 1\% rated self-reflection reports as a non-significant tool and only $8 \%$ were neutral. Question 7 was answered by only one student commenting that he/she 'needs to be more confident'.

\subsection{Instructor's journal summary}

Giving presentations supported with paper-based notes was simply not motivating enough for students to carry out a successful presentation. Even though they had been introduced to the aspects of successful presentation in the reflective practice, the old traditional way of presenting in front of the class was boring. For this reason, the learning aspect was also slow, and students were not active in the discussion part. Some students did not like this way of presenting at all.

Conversely, the group presentations supported by Prezi had the full attention of everyone in the class. The students were challenged because making presentations with Prezi required the mastery of its use and expressing creativity with the presentation layout. All students delivered authentic and inspiring presentations. The layouts they created helped them convey their presentation coherently and concisely. The audience was excited to hear and read the notes from these presentations and there was always a good discussion afterward. Both presenters and audience were more confident and performed well.

\section{DISCUSSION}

The self-assessment survey in 2017 points to the fact that the students need some more practice presenting in front of the audience on many levels. Most of the students stated that they had a good presentation structure and a good amount of material, while their use of visual aids was quite poor. Almost all students self-evaluated as having a good presentation style, but timekeeping and eye contact with the audience needs to be practiced more. However, voice quality and talking speed were to the advantage of this group. Also, discussion skills were recognized by more than half as 'Good'. And 66.7\% acknowledged that a self-assessment survey is a tool that helps them think critically of their performance.

Conversely, the self-assessment survey of 2018, shows a higher tendency of answering positively with each response. When it comes to content and organization of the presentations, as well as voice and presentation skills, more than half answered with 'Good' or better. The discussion skills were also by the vast majority labeled as 'Good'. Recognizing the value of using a self-assessment survey was also recognized as something helpful by 22 out of 25 students $(88 \%)$.

Contrasting the two results from question 6 , it can be said that in both courses students find self-reflection practice a valuable tool for thinking critically of one's performance.

However, the answers to each question (2-5) in 2018's survey suggest that the use of technology for delivering the presentation could be a determining factor for the increase in all numbers. A clear example of this is in Figures 2 and 3. Figure 2 shows higher numbers or better performance in connection to the structure of the content when Prezi is used. Also, in Figure 3, an increase in numbers means that there was a better performance in relation to the style of presentation with Prezi. 
Question 6 Contrasting answers in 2017 and 2018

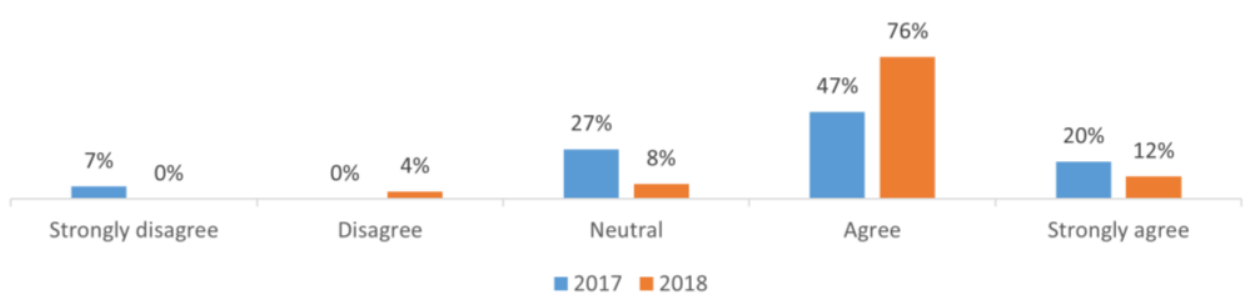

Fig. 1 Contrasting the answers from Question 6 in 2017 and 2018

\section{Content Structure}

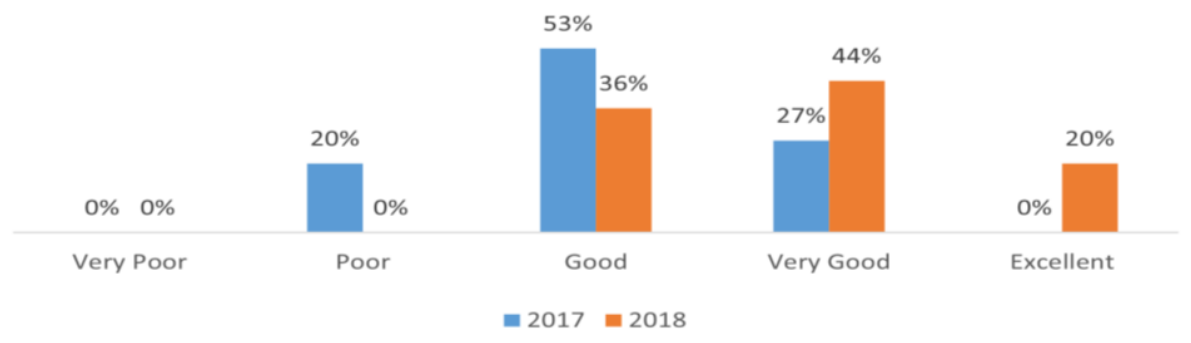

Fig. 2 Question 2 (Content structure)

\section{Presentation Skills}

Style of presentation

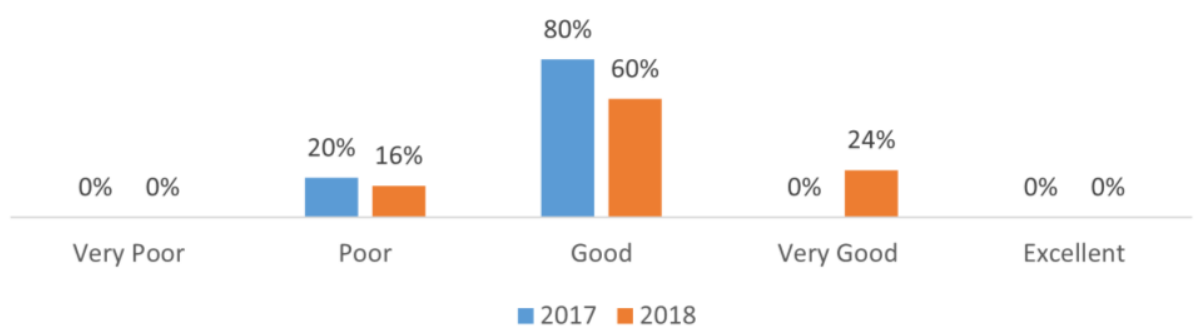

Fig. 3 Question 3 Presentation skills/Style of presentation

Nevertheless, what numbers could not reveal is the classroom atmosphere in the groups. Thus, based on the instructor's personal observation and her journal, the experimental group had more zeal to participate in the task for when Prezi is applied. There was a certain positive attitude and eagerness to deliver the presentation regardless of the lack of confidence and nervousness. Both groups displayed certain tension when speaking in front of the audience, but the group that used technology overcame the stage fright sooner than the group that had to rely just on themselves and only on the paper-based notes. The students in 2018, also demonstrated greater interest and certain excitement while waiting for the peers to present as it creates certain suspense- not knowing what and how the 
presenters would present. Prezi allowed for the students' creativity to be demonstrated as each pair had a different vision of the layout and effects. Even if not being familiar with certain software, this shows that the NET generation finds technology as a more natural and easier way to express and convey ones' message.

\section{CONCLUSION AND RECOMMENDATION}

Both study groups find that self-reflective practice per se is a quite useful tool for raising awareness of student's performance, thus improving their academic speaking skills. What is more, when a reflective practice is adequately supported by technology, it boosts students' motivation. The fact that almost all students in the self-assessment survey in 2018, selfrated their performance as quite satisfying can be attributed to the eagerness of using the online resources as a support in their learning. None of the students were familiar with using Prezi for delivering the presentation before. Nevertheless, it seems that the students found this way of presenting more natural to them, thus performed better. The instructor's journal reveals that students find the old traditional lecture-like way of delivering a presentation uninteresting. Whereas, when using Prezi, they simply engage faster and deeper. This study shows that using technology for practicing Academic speaking is indeed a particularly good way to motivate students towards their goals. Also, this study opens the door to further research. Since this study involves a small number of students, there is a need for the study to be repeated with a larger sample and possibly with an equal number of participants in both groups.

\section{REFERENCES}

Abdulrahman, Tryanti. "TED talks as listening teaching strategy in EAP classroom." The Asian ESP Journal (2018): 60.

Akbari, Ramin, Behzadpoor Foad, and Dadvand Babak. "Development of English language teaching reflection inventory." System 38, no. 2 (2010): 211-227.

Albino, Gabriel. "Improving speaking fluency in a task-based language teaching approach: The case of EFL learners at PUNIV-Cazenga." SAGE Open 7, no. 2 (2017): 2158244017691077.

Birjandi, Parviz, and Nasrin Hadidi Tamjid. "The Role of Self-Assessment in Promoting Iranian EFL Learners' Motivation." English Language Teaching 3, no. 3 (2010): 211-220.

Burns, Anne. Doing action research in English language teaching: A guide for practitioners. Routledge, 2009.

Cohen-Sayag, Etty, and Fischl Dita. "Reflective Writing in Pre-Service Teachers' Teaching: What Does It Promote?." Australian Journal of Teacher Education 37, no. 10 (2012): 2.

Conway, F. Paul. "Anticipatory reflection while learning to teach: From a temporally truncated to a temporally distributed model of reflection in teacher education." Teaching and teacher education 17, no. 1 (2001): 89-106.

Darginavičienè, Irena, and Jolita Šliogerienè. "Learners’ Perceptions of Performance in Major Speaking Activities at Tertiary Level." (2020). The journal of teaching English for specific and academic purposes, Vol. 8, No2, 2020, pp. 135-145

Derakhshan, Ali, Khalili Atefeh Nadi, and Beheshti Fatima. "Developing EFL learner's speaking ability, accuracy and fluency." English Language and Literature Studies 6, no. 2 (2016): 177-186. 
Desautel, Daric. "Becoming a Thinking Thinker: Metacognition, Self-Reflection, and Classroom Practice." Teachers College Record 111, no. 8 (2009): 1997-2020.

Gottlieb, Margo. "Nurturing Student Learning Through Portfolios." TESOL journal 5, no. 1 (1995): 12-14.

Hamad, Mona M., Amal Abdelsattar Metwally, and Sabina Yasmin Alfaruque. "The Impact of Using YouTubes and Audio Tracks Imitation YATI on Improving Speaking Skills of EFL Learners." English Language Teaching 12, no. 6 (2019): 191-198.

Haukås, Åsta, Bjørke Camilla, and Dypedahl Magne. Metacognition in language learning and teaching. Routlege, 2018.

Hollingsworth, Hilary, and Clarke David. "Video as a tool for focusing teacher selfreflection: Supporting and provoking teacher learning." Journal of Mathematics Teacher Education 20, no. 5 (2017): 457-475.

Khotimah, Siti. "THE USE OF PROBLEM BASED LEARNING TO IMPROVE STUDENTS'SPEAKING ABILITY." In ELT Forum: Journal of English Language Teaching, vol. 3, no. 1. 2014.

Kizilcik, Hale, and Daloglu Aysegul. "Implementing an Interactive Reflection Model in EAP: Optimizing Student and Teacher Learning through Action Research." Australian Journal of Teacher Education 43, no. 9 (2018): 1-27.

LaBoskey, Vicki Kubler. Development of reflective practice: A study of preservice teachers. New York: Teachers College Press, 1994.

Lancini, Simone. "The use of android and ios voice tools to develop english for academic purposes (eap): speaking skills for non-native speakers of english." EntreLínguas 5, no. 1 (2019): 63-76.

Lo, Ya-Fen. "Implementing reflective portfolios for promoting autonomous learning among EFL college students in Taiwan." Language Teaching Research 14, no. 1 (2010): 77-95.

Mynard, Jo. "A blog as a tool for reflection for English language learners." The Philippine ESL Journal 1, no. 1 (2008): 77-90.

Nunes, Alexandra. "Portfolios in the EFL classroom: disclosing an informed practice." ELT Journal 58, no. 4 (2004): 327-335.

Orlova, Natalia. "Video Recording as a Stimulus for Reflection in Pre-Service EFL Teacher Training." In English Teaching Forum, vol. 47, no. 2, pp. 30-35. US Department of State. Bureau of Educational and Cultural Affairs, Office of English Language Programs, SA-5, 2200 C Street NW 4th Floor, Washington, DC 20037, 2009.

Osborn, Terry. Critical reflection and the foreign language classroom. IAP, 2005.

Paulson, F. Leon, Paulson R. Pearl., and Carol A. Meyer. "What makes a portfolio a portfolio." Educational leadership 48, no. 5 (1991).

Pardede, Parlindungan. "Action research in EFL Learning and Teaching." (2019): 136-146.

Porto, Melina. "Learning diaries in the English as a foreign language classroom: A tool for accessing learners' perceptions of lessons and developing learner autonomy and reflection." Foreign Language Annals 40, no. 4 (2007): 672-696.

PREZI. Accessed 17/01/2021/www.prezi.com

Rodríguez Ochoa, Edgar Orlando.2007."Self-assessment Practices: An Empowering Tool in the Teachingand Learning EFL Processes."Colombian Applied Linguistics Journal 9: 229-246.http://www.scielo.org.co/pdf/calj/n9/n9a12.pdf 
Rokni, Seyed Jalal Abdolmanafi, and Seifi Asieh. "The effect of dialog journal writing on EFL learners' grammar knowledge." Journal of Language and Linguistic Studies 9, no. 2 (2014): 57-67.

THE SCIENCE OF EFFECTIVE PRESENTATION. Prezi. Accessed on 17/01/2021: https://prezi.com/thescience/?click_source=logged_element\&page_location=header_ why_prezi_dropdown\&element_text=the_science

Trif, Letitia, and Popescu Teodora. "The reflective diary, an effective professional training instrument for future teachers." Procedia-Social and Behavioral Sciences 93 (2013): 1070-1074.

Tuan, Luu Trong. "Enhancing EFL Learners' Writing Skill via Journal Writing." English Language Teaching 3, no. 3 (2010): 81-88.

Yang, Nae-Dong. "Integrating portfolios into learning strategy-based instruction for EFL college students." International Review of Applied Linguistics in Language Teaching 41, no. 4 (2003): 293-317.

Young, A. Terrell, and Crow, Mary Lynn (1992). Using dialogue journals to help students deal with their problems. Clearing House, 65(5),307-10.

Zeichner, Ken, and Liu Katrina Yan. "A critical analysis of reflection as a goal for teacher education." In Handbook of reflection and reflective inquiry, pp. 67-84. Springer, Boston, MA, 2010.

Zou Bin, Liviero Sara, Hao Mengyuan, and Wei Chaoyang. "Artificial Intelligence Technology for EAP Speaking Skills: Student Perceptions of Opportunities and Challenges." In Technology and the Psychology of Second Language Learners and Users, pp. 433-463. Palgrave Macmillan, Cham, 2020. 